\title{
Surgical Antimicrobial Prophylaxis Challenges in translating evidence to practice
}

"Seif S. Al-Abri ${ }^{1}$ and Mamoun Elsheikh ${ }^{2}$

$$
\text { الوقاية بالمضادات الحيوية في الجراحة }
$$

سيف سالم العبري و مأمون الشيخ

S URGICAL-SITE INFECTIONS (SSIS) ARE ONE of the most common healthcare-associated infections, accounting for $31 \%$ of all healthcareassociated infections worldwide. ${ }^{1}$ It is estimated that $2-5 \%$ of patients undergoing surgery develop SSIs, with a higher percentage estimated in resourcelimited healthcare settings. ${ }^{2}$ The impact of SSIs on healthcare delivery systems is very severe, resulting in prolonged hospitalisation, complex medical treatments, increased readmissions and outpatient visits as well as increased direct and indirect medical costs. ${ }^{3,4}$ In addition, these factors result in significant morbidity and mortality. ${ }^{3,4}$ Previous research indicates that approximately $60-80 \%$ of SSIs are preventable through the implementation of evidence-based practices such as surgical antimicrobial prophylaxis (SAP) guidelines. ${ }^{5}$

The key to preventing SSIs lies in the understanding and careful implementation of SAP guidelines. Choosing the right antibiotic for each case is of particular importance, as the right antibiotic will produce adequate serum and tissue drug levels and exceed the minimal inhibitory concentration for any organisms that are likely to be encountered during the operation. Optimal timing of the antibiotic prophylaxis administration is considered to be 30-60 minutes before the first incision is made, except for certain antibiotics (e.g. vancomycin and ciprofloxacin) which are administered 120 minutes beforehand. ${ }^{6}$ Bratzler et al. have confirmed that a single dose of an antimicrobial agent is sufficient for most surgical operations. ${ }^{6}$ Although the principles of antimicrobial prophylaxis in surgery are clearly established and several guidelines have been published, the implementation of these guidelines remains problematic and controversial among surgeons. ${ }^{7}$ The overprescription and inappropriate timing and duration of antimicrobials remains a significant issue in the practice of surgical prophylaxis. In addition, the incidence of SSIs has increased and new antimicrobialresistant bacteria have emerged due to poor adherence to SAP guidelines. ${ }^{8,9}$

The aforementioned challenges have been widely addressed in many developed countries, ${ }^{10}$ although very little attention has been given to this issue in developing countries and the Middle Eastern region. In the November 2015 issue of SQUMJ, Telfah et al. published a report on the impact of a multidisciplinary quality improvement project on the adherence to SAP guidelines in the treatment of surgical oncology patients. ${ }^{10} \mathrm{~A}$ clinical pharmacist was noted to play a key role in updating the SAP guidelines and providing the surgeons with required prophylaxis education. Telfah et al. concluded that there was significant improvement in the adherence to SAP guidelines following the implementation of the multidisciplinary quality improvement project. ${ }^{10}$ This approach demonstrates the important role of both clinical pharmacists and surgeons in engaging with and improving adherence to SAP guidelines. ${ }^{7,11}$

A review of studies evaluating guideline implementation strategies found only modest-to-moderate effects and noted that healthcare organisations' resources for guideline implementation were usually insufficient to allow much more than the dissemination of educational materials or lunchtime educational meetings, interventions whose effects were usually only short-lived. ${ }^{12}$ Barlow et al. found that education and audit-based interventions used before the implementation of guidelines resulted in a significant increase in appropriate antibiotic prescriptions after the introduction of a multifaceted education programme. ${ }^{13}$ Audit feedback systems to improve the quality of care have also been shown to be feasible and effective in hospital settings in low-income countries. ${ }^{14}$ Consequently, successful guideline implementation 
programmes need to understand local barriers, incorporate multiple-component interventions and proceed within a framework of continuous quality improvement. ${ }^{12}$

Although SAP plays an important role in reducing the rate of SSIs, other factors must be taken into consideration. These include attention to basic infection control strategies; the experiences and techniques of the surgeon; the duration of a procedure; hospital and operating room environments; instrument-sterilisation procedures; preoperative preparation techniques (e.g. surgical scrubs, skin antisepsis and appropriate hair removal); perioperative management of patient temperature and glycaemic control; and the underlying medical condition of the patient. ${ }^{6}$

In conclusion, drafting SAP guidelines without addressing the implementation process will not necessarily decrease SSI rates. To achieve optimal adherence, antibiotic policy-makers should develop evidence-based guidelines in collaboration with surgeons, guarantee an effective distribution of those guidelines, perform periodic audits on adherence to the guidelines and provide feedback from these audits to surgeons and the appropriate authorities. Hospitals also need to establish a SSI surveillance system, formulate a multidisciplinary implementation team and monitor antimicrobial consumption related to surgical procedures. Moreover, education and training on SSI prevention and management, including SAP guidelines, should be integrated in all undergraduate and postgraduate surgical training programmes.

\section{References}

1. Burke JP. Infection control: A problem for patient safety. N Engl J Med 2003; 348:651-6. doi: 10.1056/NEJMhpr020557.

2. Mu Y, Edwards JR, Horan TC, Berrios-Torres SI, Fridkin SK. Improving risk-adjusted measures of surgical site infection for the national healthcare safety network. Infect Control Hosp Epidemiol 2011; 32:970-86. doi: 10.1086/662016.

3. de Lissovoy G, Fraeman K, Hutchins V, Murphy D, Song D, Vaughn BB. Surgical site infection: Incidence and impact on hospital utilization and treatment costs. Am J Infect Control 2009; 37:387-97. doi: 10.1016/j.ajic.2008.12.010.
4. Leaper DJ, van Goor H, Reilly J, Petrosillo N, Geiss HK, Torres AJ, et al. Surgical site infection: A European perspective of incidence and economic burden. Int Wound J 2004; 1:24773. doi: 10.1111/j.1742-4801.2004.00067.x.

5. Anderson DJ. Surgical site infections. Infect Dis Clin North Am 2011; 25:135-53. doi: 10.1016/j.idc.2010.11.004.

6. Bratzler DW, Dellinger EP, Olsen KM, Perl TM, Auwaerter PG, Bolon MK, et al. Clinical practice guidelines for antimicrobial prophylaxis in surgery. Am J Health Syst Pharm 2013; 70: 195-283. doi: 10.2146/ajhp120568.

7. Tourmousoglou CE, Yiannakopoulou ECh, Kalapothaki V, Bramis J, St Papadopoulos J. Adherence to guidelines for antibiotic prophylaxis in general surgery: A critical appraisal. J Antimicrob Chemother 2008; 61:214-8. doi: 10.1093/jac/ dkm406.

8. Kernodle DS, Barg NL, Kaiser AB. Low-level colonization of hospitalized patients with methicillin-resistant coagulasenegative staphylococci and emergence of the organisms during surgical antimicrobial prophylaxis. Antimicrob Agents Chemother 1988; 32:202-8. doi: 10.1128/AAC.32.2.202.

9. Terpstra S, Noordhoek GT, Voesten HG, Hendriks B Degener JE. Rapid emergence of resistant coagulase-negative staphylococci on the skin after antimicrobial prophylaxis. J Hosp Infect 1999; 43:195-202. doi: 10.1053/jhin.1999.0636.

10. Telfah S, Nazer L, Dirani M, Daoud F. Improvement in adherence to surgical antimicrobial prophylaxis guidelines after implementation of a multidisciplinary quality improvement project. Sultan Qaboos Univ Med J 2015; 15:e523-7. doi: 10.18295/squmj.2015.15.04.014.

11. Ozgun H, Ertugrul BM, Soyder A, Ozturk B, Aydemir M. Perioperative antibiotic prophylaxis: Adherence to guidelines and effects of educational intervention. Int J Surg 2010; 8:159-63. doi: 10.1016/j.ijsu.2009.12.005.

12. Al-Abri SS, Al-Maashani S, Memish ZA, Beeching NJ. An audit of inpatient management of community-acquired pneumonia in Oman: A comparison with regional clinical guidelines. J Infect Public Health 2012; 5:250-6. doi: 10.1016/j.jiph.2012.03.002.

13. Barlow G, Nathwani D, Myers E, Sullivan F, Stevens N, Duffy $R$, et al. Identifying barriers to the rapid administration of appropriate antibiotics in community-acquired pneumonia J Antimicrob Chemother 2008; 61:442-51. doi: 10.1093/jac/ $\mathrm{dkm} 462$.

14. Wahlström R, Kounnavong S, Sisounthone B, Phanyanouvong A, Southammavong T, Eriksson B, et al. Effectiveness of feedback for improving case management of malaria, diarrhoea and pneumonia: A randomized controlled trial at provincial hospitals in Lao PDR. Trop Med Int Health 2003; 8:901-9. doi: 10.1046/j.1365-3156.2003.01105.x. 